\title{
Southern California Seismic Network Update
}

\author{
Kate Hutton, Egill Hauksson, John Clinton, Joseph Franck, Anthony \\ Guarino, and Nick Scheckel \\ Seismological Laboratory, California Institute of Technology
}

\author{
Doug Given and Alan Yong \\ Pasadena Field Office, U.S. Geological Survey
}

\section{INTRODUCTION}

The authoritative region of the Southern California Seismic Network (SCSN) extends across southern California, from the U.S./Mexico international border to Coalinga and Owens Valley in central California (Figure 1). This area contains almost 20 million inhabitants, including two of the ten largest cities in the United States (Los Angeles and San Diego) and the two largest harbors (Los Angeles and Long Beach) in the nation. SCSN also reports on earthquakes in Baja California, which could potentially cause damage in the U.S. More than fifty earthquakes (not including aftershocks) are felt each year, and an average of 1.5 events per year are potentially damaging (magnitude greater than 5.0). Immediately after a moderate or large earthquake, SCSN provides information about the size, location, and distribution of ground shaking. Emergency managers use this information to coordinate rescue operations, guide inspectors in the search for damage, and satisfy the public's need for information. The historical record of earthquake occurrences in California is important to insurers, geotechnical engineers, and city planners.

SCSN has maintained and published a catalog of earthquakes complete above about magnitude 3.0 since 1932, and above about magnitude 1.8 since the late 1970 's, with relatively consistent magnitudes (mostly $M_{L}$ ) over the whole time period. Digital seismograms are available since the late 1970's, and selected seismograms since 1962 have been scanned.

Much has changed in SCSN since the last Network Bulletin (Wald et al., 1998) was published, which described changes that took place during 1997. More than half the new stations have modern broadband sensors and strong-motion sensors, and dataloggers with continuous telemetry. Many of the remaining analog stations are digitized on Earthworm hubs (Johnson et al., 1995) at field sites and telemetered to the dataprocessing facility in Pasadena, California. Online and offline data processing has been converted completely from the CUSP (Caltech-USGS Seismic Processing) system to TriNet software (Hauksson et al., 2001). The new TriNet software uses Oracle as the database, and most of the code development was done in $\mathrm{C}++$. Earthquake parametric information and waveforms are normally available to users within a few minutes of the occurrence of an earthquake. To accomplish its mission, SCSN continues to develop and operate a reliable, modern system for earthquake monitoring, archiving, and distribution of information for improved public safety, emergency response, loss mitigation, and scientific research.

SCSN is operated jointly by the Pasadena office of the U.S. Geological Survey and the Seismological Laboratory at the California Institute of Technology. SCSN is a partner of the California Integrated Seismic Network (CISN), which in turn is the California region of the Advanced National Seismic System (ANSS). Signals from more than 370 remote seismic stations in southern California are transmitted via various telemetry paths to central computers at the Seismological Laboratory in Pasadena, where they are processed to yield phases, earthquake locations and magnitudes, archived seismograms, and ultimately data "products" such as ShakeMaps (Wald et al., 1999) and moment-tensor solutions (Clinton et al., 2005). Waveform, phase, and catalog data are archived and distributed by the Southern California Earthquake Data Center (SCEDC). In this paper we summarize the main network developments and the seismicity of the region in recent years.

\section{STATIONS}

SCSN now operates 159 digital stations with broadband and strong-motion sensors, 132 (digitized) analog stations with short-period sensors, and 20 digital stations with strong-motion sensors and in a few cases also short-period sensors (Figure 1). Added, deleted, and changed stations for 2004 and 2005 are shown in Table 1. In addition, real-time, continuous data were imported from 16 stations from the Anza area via UC San Diego, 18 stations from the University of Nevada at Reno, 16 stations from the National Strong-Motion Program, and six stations from the California Geological Survey. The short-period stations include five stations from the California Division of Water Resources and six from the Northern California Seismic Network (NCSN). We also received data from 15 stations in 


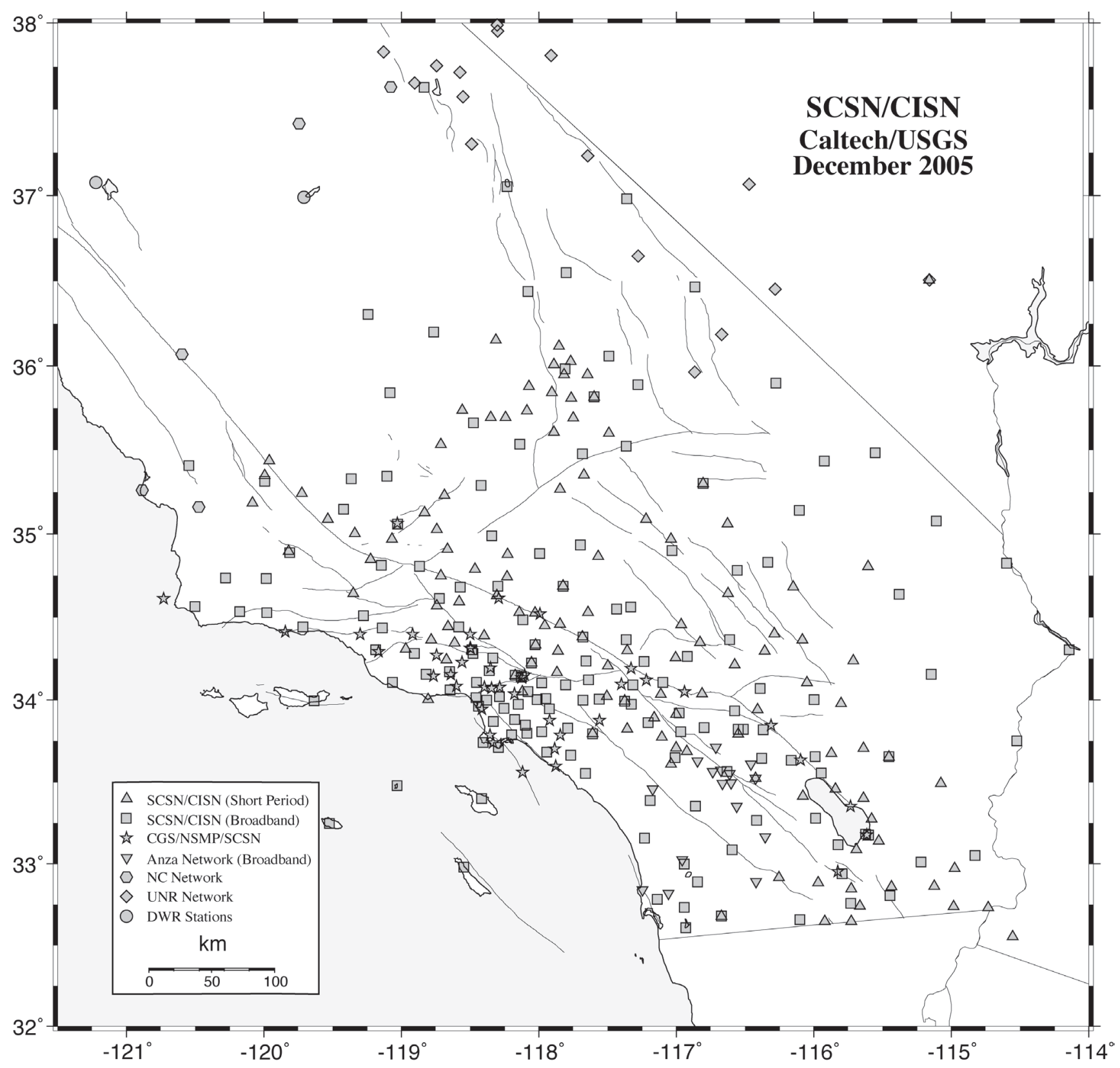

A Figure 1. Seismic stations recorded by SCSN. Most stations are operated by SCSN, while some are operated by other agencies such as UCSD Anza network, University of Nevada at Reno, and Department of Water Resources.

the U.C. Berkeley Digital Seismic Network, to ensure minimal statewide monitoring capability in case of a major failure of monitoring capability in northern California. Similarly, we export data from 15 SCSN stations to UC Berkeley Seismological Laboratory to provide back-up for southern California.

The 159 broadband stations are each equipped with one of three different types of three-component broadband sensors (long-period corner of $30 \mathrm{~s}, 120 \mathrm{~s}$, and $360 \mathrm{~s}$ ), a three-component strong-motion sensor, and a datalogger. Most stations are sampled at $100 \mathrm{sps}$, the others at $80 \mathrm{sps}$. The instrument responses are available from http://www.data.scec.org/.

To transmit the data from the remote sites, we use a mixture of commercial frame-relay service, $\mathrm{T} 1$ circuits, microwave communications provided by local utilities, and the Internet. Much of the analog station data are transmitted via analog radio telemetry to one of five remote Earthworm digitizer hubs (Johnson et al., 1995), where the signals are digitized and transmitted to Pasadena via frame-relay or Internet telemetry circuits. Signals from other analog stations are transmitted all the way to Pasadena, where they are digitized by an Earthworm digitizer, at 100 sps.

\section{DATA PROCESSING}

All the digitized waveform data are processed by algorithms on a pair of real-time computers, a primary system and a back-up. 
TABLE 1

Additions and Deletions to SCSN in 2004 and 2005

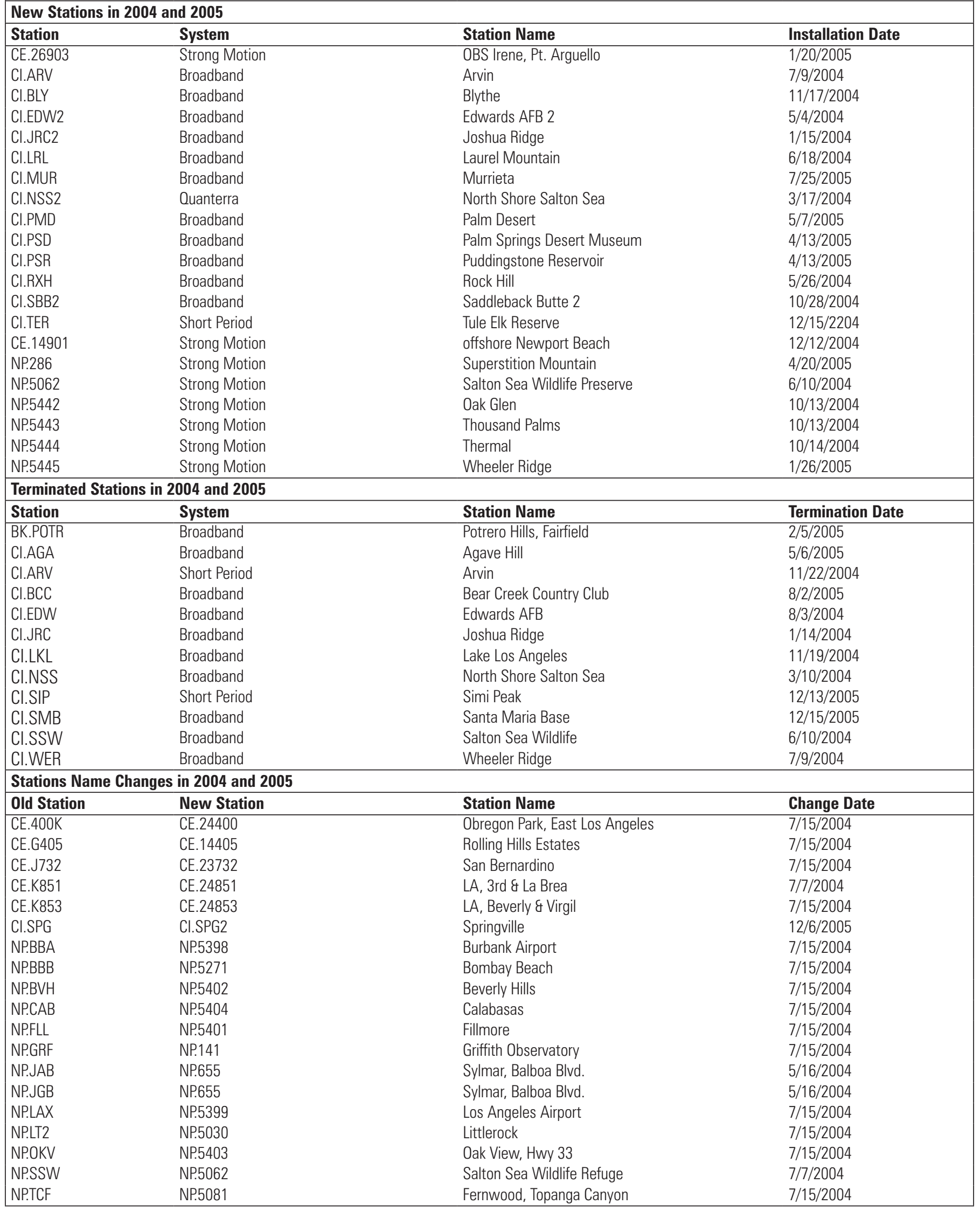


Two earthquake event-detection processing threads operate in parallel. The first thread uses Earthworm P-picker/associator/Hypoinverse locator algorithms, which detect, locate, and compute magnitudes for the earthquakes. Most earthquakes above magnitude 1.8 are detected in this fashion. A parallel, more sensitive, thread uses the Earthworm subnet trigger algorithm, which detects most of the same events, plus a number of smaller events missed by the first thread. Parametric information and waveform files are available immediately on a pair (primary and back-up) of Data Center computer systems for archiving and distribution.

If the real-time system results meet quality control criteria for location and magnitude, earthquake "alarm" notifications are sent to various clients, which include the Quake Data Distribution System (QDDS) that delivers information to the "Recent Earthquake" map Web sites operated by the U.S. Geological Survey, the CUBE (Caltech-USGS Broadcast of Earthquakes notification system), the CISN Display software, and the ShakeMap system. SCSN also distributes e-mail notification directly to critical users, and through a public e-mail subscription list with sign-up available from the http://www. cisn.org/Web page.

A duty seismologist is on call 24 hours a day and responds when earthquake alarms are issued. The duty seismologist may confirm, modify, or withdraw the alarm. In addition, all phase arrival times, locations, amplitudes, and magnitudes are reviewed by a seismic analyst, usually on the same day, and always within one week.

\section{FOCAL MECHANISMS}

SCSN produces both first-motion mechanisms and centroid moment-tensor (CMT) solutions for larger earthquakes (Clinton et al., 2005). The first-motion mechanisms are more reliable for small earthquakes, whereas the moment tensors are more reliable for large $(M \geq 4.0)$ earthquakes.

\section{Moment Tensors}

Automatically generated moment-tensor solutions have recently been added to the suite of real-time products produced by SCSN (Clinton et al., 2005). The moment magnitude, $M_{w}$, and moment tensor are both available within minutes for all regional earthquakes with $M_{L}>4.0$, and in many cases for events between $M_{L} 3.5-4.0$. The method uses the 1D Time-Domain INVerse Code (TDMT INVC) software package developed by Doug Dreger (see Dreger and Helmberger, 1990) for real-time application by the UC Berkeley Seismological Laboratory. The algorithm uses Green's functions for various velocity profiles in southern California to invert the observed three-component broadband waveforms filtered from $10 s-100 s$, for three to five stations. Automatic solutions have an assigned quality factor which depends on the number of stations in the inversion and the goodness of fit between synthetic and observed data. Depending on the quality, the $M_{w}$ and moment tensor may be automatically distributed to users via e-mail, and to QDDS for display on the USGS Recent Earthquakes Web page (http://quake.wr.usgs.gov/recenteqs/latestfault.htm) and CISN Display. The duty seismologists can review the automatically generated solution via a Web interface and determine whether it meets the minimum requirements for an immediate distribution. Different stations may be selected and the inversion rerun to optimize the solution. If a minimum quality factor is attained and the event is in the southern California reporting region, the $M_{w}$ can become the official SCSN/CISN magnitude. During 2004, however, manual insertion of the $M_{w}$ was required.

The real-time moment-tensor algorithm has been applied to the SCSN catalog for all regional events with $M_{L}>3.5$, and local events with $M_{L}>3.0$ since September 1999. The method reliably produces a $M_{w}$ for local events with $M_{L}>3.5$, and moment tensors for $M_{L}>4.0$. The algorithm also provides excellent back-up solutions for large events at regional distances, such as in northern California, Nevada, and Baja California.

\section{First-motion Solutions}

First-motion lower-hemisphere focal mechanisms are determined for most local earthquakes of $M_{L}>2.5$ (Figures 2 and 3). These solutions are posted on the USGS Recent Earthquakes Web page. We used the grid-searching algorithm and computer programs (FPFIT) by Reasenberg and Oppenheimer (1985) to determine the first-motion focal mechanisms. If the epicentral location is within the boundaries of SCSN, the first-motion mechanisms are generally well constrained using the analyst's phases. They are not as well constrained using automatic picks. The average uncertainties in strike, dip, and rake of the focal mechanisms are approximately $10^{\circ}, 20^{\circ}$, and $30^{\circ}$.

\section{SEISIMICITY}

\section{Location Practice}

All phase picks are reviewed by a seismic analyst. Automatic picks from the real-time system are retained if they are correct and derived from the component with the clearest arrival. All others are replaced or added manually, using a Java-based graphical user interface called Jiggle. The operational standards call for picking all impulsive arrivals and reasonably well constrained ("E2") emergent arrivals. Hypoinverse (2002) is used for the locations. For events with nearby stations, distance weighting begins at $80 \mathrm{~km}$, and no stations beyond $120 \mathrm{~km}$ are used.

For routine catalog locations (used in the SCEDC searchable catalog at http://www.data.scec.org/catalog_search/date_ mag_loc.php), a uniformly layered velocity model (Hadley and Kanamori, 1977) is used. The Hadley-Kanamori velocity model is not appropriate for deep sedimentary basins, such as the Los Angeles Basin and the Imperial Valley, where the routine locations are mislocated to varying degrees. Raw locations can be unrealistically deep, with depths up to $30 \mathrm{~km}$ or more. The analysts may constrain an earthquake's depth to a reasonable value for the source area, which results in higher RMS values. Although the use of station delays would help account for low-velocity sedimentary layers, we do not use station delays at this time.

We later relocate the events using a three-dimensional velocity model (Hauksson, 2000). These locations are made 


\section{Southern California Seismicity 2004}

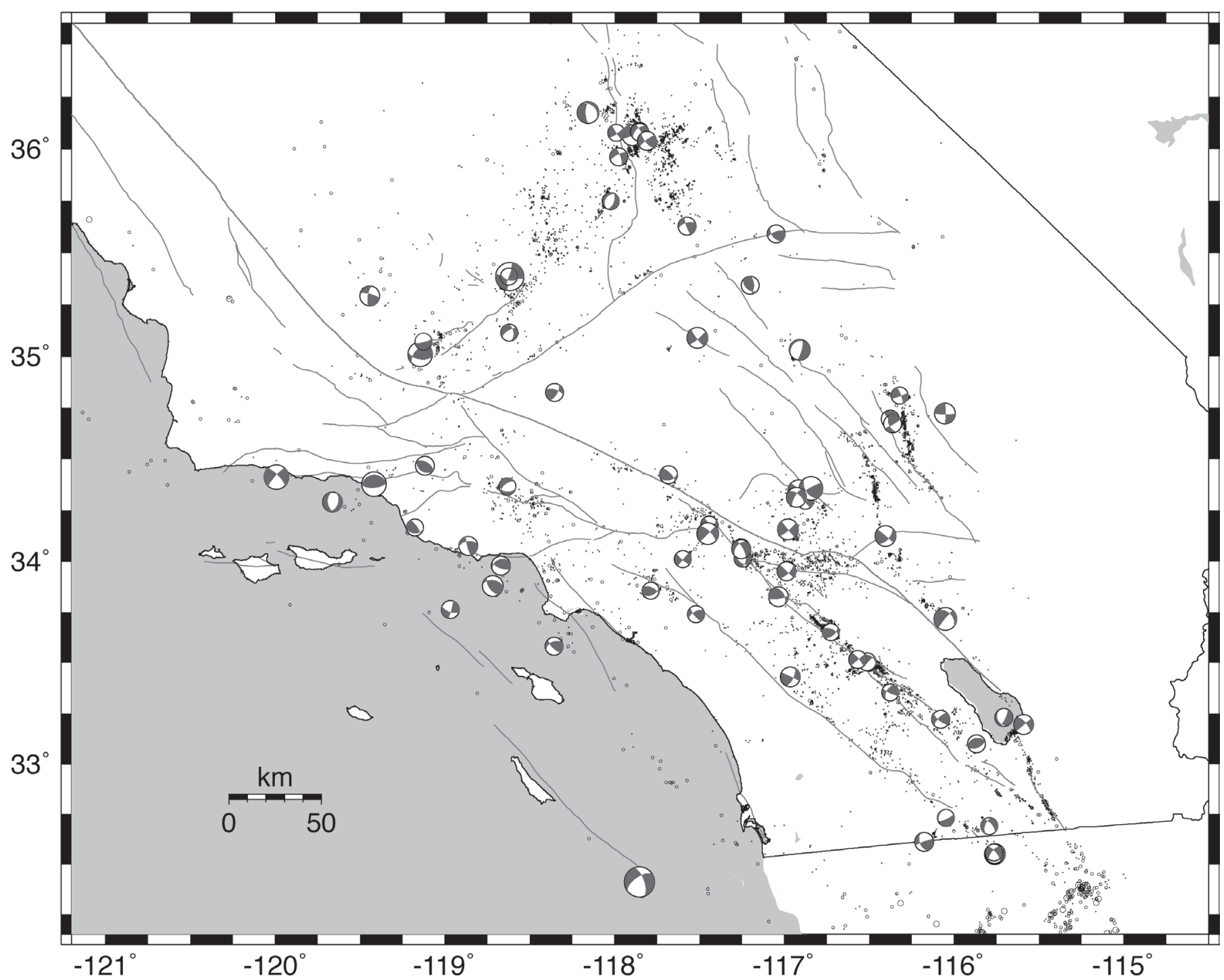

$\Delta$ Figure 2. Seismicity map showing more than 11,000 local earthquakes recorded during 2004. First-motion focal mechanisms are included for most events over $M_{L} 3.0$.

available as one of the "alternative catalogs" on the SCEDC Web site (http://www.data.scec.org/).

\section{Magnitude Practice}

Most earthquakes in our catalog larger than about magnitude 1.8 are assigned $M_{L}$ (local) magnitudes. Although $M_{w}$ is computed for most earthquakes with magnitudes 4.0 and larger, during the period of this report, they were used only as the preferred magnitude for 5.0 or larger. The $M_{L}$ 's are based on synthetic Wood-Anderson amplitudes from the broadband horizontal channels (Richter, 1935; see Kanamori et al., 1993). For the smallest earthquakes, too few broadband channels are available to compute $M_{L}$; in these cases, the analyst currently inserts a "hand" magnitude $\left(M_{h}\right)$, which is a duration magnitude similar to $M_{d}$. Work is currently underway to calibrate duration magnitude $M_{d}$ for the network.

\section{Earthquakes of Interest}

Southern California seismic activity has been quiet over the last few years. The aftershock zones of the 1992 Landers earthquake $\left(M_{w} 7.3\right)$ and the 1999 Hector Mine earthquake $\left(M_{w} 7.1\right)$ are still faintly visible in the seismicity maps (Figures 2 and 3 ). That of the 1994 Northridge earthquake $\left(M_{w} 6.7\right)$ is barely visible.

During 2004, SCSN detected and processed 11,682 earthquakes, of which 11,499 were located inside the SCSN region. Of these, 1,283 had a magnitude of 2.0 or larger, 127 had a magnitude of 3.0 or larger, and eight were greater than or equal to magnitude 4.0. In addition, we processed 672 quarry and mine blasts.

In 2005 , the seismicity was only slightly higher. 12,451 earthquakes were detected and processed, of which 1,650 had a magnitude of 3.0 or larger, 177 had a magnitude of 3.0 or larger, and 27 had a magnitude of 4.0 or larger; 642 quarry and mine 


\section{Southern California Seismicity 2005}

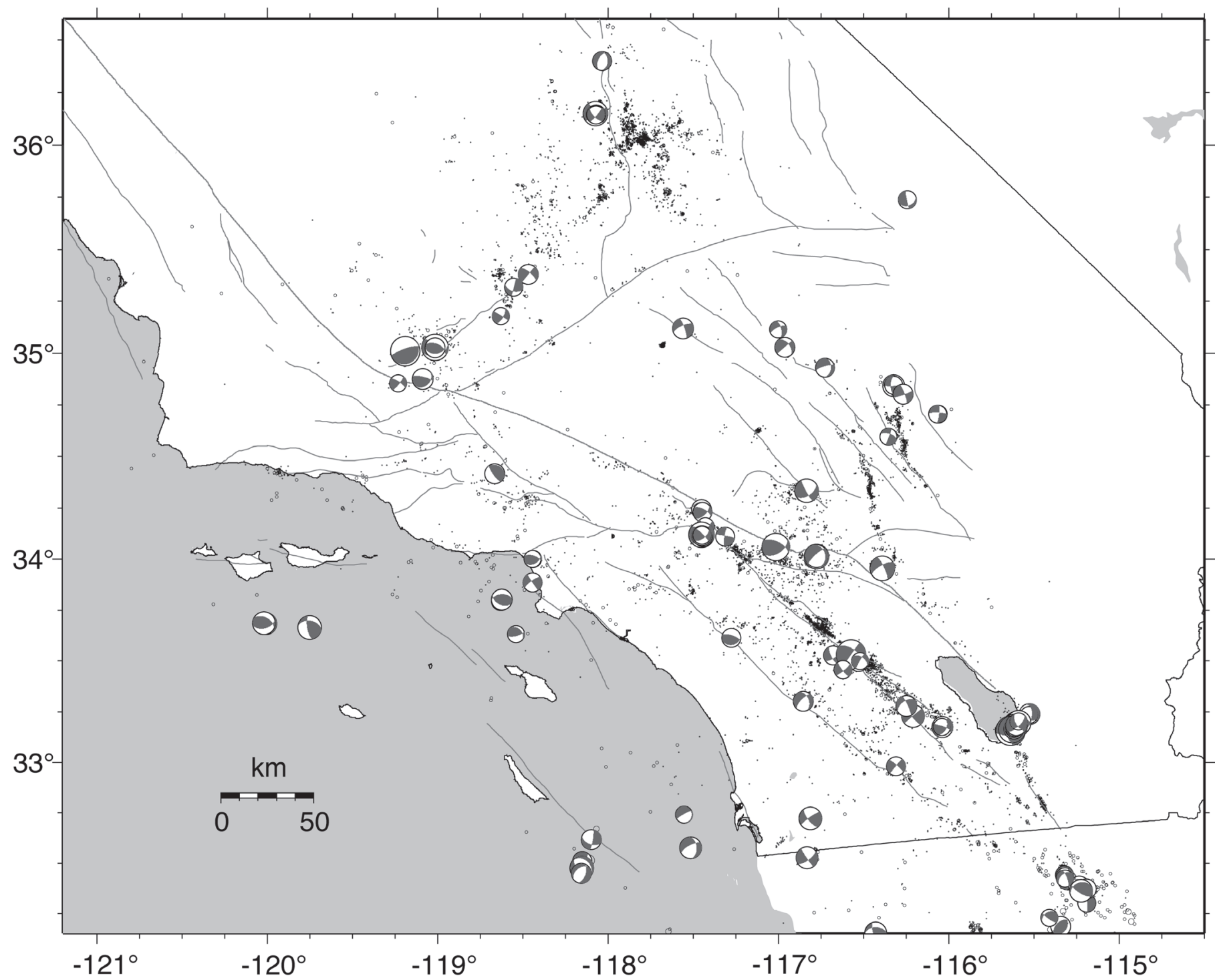

A Figure 3. Seismicity map showing more than 12,000 local earthquakes recorded during 2005 . First-motion focal mechanisms are included for most events over $M_{L} 3.0$.

blasts were processed. These seismicity rates are a factor of two lower than the average rate during the 1990's.

\section{Highlights of the $\mathbf{2 0 0 4}$ and $\mathbf{2 0 0 5}$ seismicity include:}

- 15 June $2004 M_{w}$ 5.3, 44 miles west-southwest of Coronado (14065544)

- 28 September $2004 M_{w}$ 6.0, 9 miles south of Parkfield (51147892)

- 29 September $2004 M_{w} 5.0,11$ miles north-northwest of Keene (14095628)

- 16 April $2005 M_{w}$ 5.2, 13 miles west of Wheeler Ridge (14138080)

- 12 June $2005 M_{w}$ 5.2, 6 miles east-southeast of Anza (14151344)
- 1 September $2005 M_{w} 5.1,1$ mile south of Obsidian Butte (14179736)

\section{“MOLDY OLDIES"}

In addition to processing earthquake data as they are recorded, we have made much progress on backlogs of unprocessed or partially processed events from the 1980's and earlier.

- 1932-1978: All earthquakes on the phase cards were entered into the CUSP system, relocated, and transferred to the SCEDC database. Some events (close aftershocks) not on the phase cards have yet to be inserted, and some of the data need to be checked for quality and completeness. This period, however, is searchable, and the phase data are available online. 
- 1979-1980: All available waveform, phase, and hypocenter data were loaded into a test database, where we are currently relocating events and sorting out multiple copies.

- 1981, 1983: A complete list of events is available in the database. Wood-Anderson amplitudes still need to be incorporated, so some magnitudes may change.

- 1982, 1984-present: Only minor changes have been made, particularly in the Joshua Tree and Landers aftershock sequences. In particular, some magnitudes incorrectly estimated to be over M3 have been revised. This work continues.

\section{FOR FURTHER INFORMATION}

The data, including catalog search capability, phases, waveforms, and the instrument response characteristics, are available through the Southern California Earthquake Data Center (http://www.data.scec.org/). \&

\section{ACKNOWLEDGMENTS}

SCSN operations are funded by the USGS internal and external programs, through cooperative agreement 04HQAG0010. SCSN also receives operation funds from the California Governor's Office of Emergency Services, through Std Agreement 6028-2, and Caltech's Earthquake Research Affiliates Program. The EarthScope USArray program supports maintenance for selected stations through subaward No. 475 with IRIS, and some new development is supported through subaward 310 with IRIS. Caltech Seismological Laboratory contribution number 9113.

\section{REFERENCES}

Clinton, J. F., E. Hauksson, and K. Solanki (2005). Automatically generated moment tensor solutions for southern California: Robustness of the Mw magnitude scale and style of faulting, Bulletin of the Seismological Society of America (submitted).

Dreger, D. S. and D. V. Helmberger (1990). Broadband modeling of local earthquakes, Bulletin of the Seismological Society of America 80, $1,162-1,179$.

Hadley, D. and H. Kanamori (1977). Seismic structure of the Transverse Ranges, California, Geological Society of America Bulletin 88, $1,469-1,478$.
Hauksson, E. (2000). Crustal structure and seismicity distribution adjacent to the Pacific and North American plate boundary in southern California, Journal of Geophysical Research 105, 13,875-13,903.

Hauksson, E., P. Small, K. Hafner, R. Busby, R. Clayton, J. Goltz, T. Heaton, K. Hutton, H. Kanamori, J. Polet, D. Given, L. M. Jones, and D. Wald, (2001). Southern California Seismic Network: Caltech/ USGS element of TriNet 1997-2001, Seismological Research Letters 72, 697-711.

Johnson, C. E., A. Bittenbinder, B. Boegart, L. Dietz, and W. Kohler (1995). Earthworm: A flexible approach to seismic network processing, IRIS Newsletter XIV(2), 1-4.

Kanamori, H., J. Mori, E. Hauksson, T. H. Heaton, L. K. Hutton, and L. M. Jones (1993). Determination of earthquake energy release and $\mathrm{M}_{\mathrm{L}}$ using TERRAscope, Bulletin of the Seismological Society of America 83, 330-346.

Klein, F. W. (2002). User's Guide to HYPOINVERSE-2000, a Fortran Program to Solve for Earthquake Locations and Magnitudes, U.S. Geological Survey Open-File Report 02-171.

Reasenberg, P. and D. Oppenheimer (1985). FPFIT, FPPLOT and FPPAGE: Fortran Computer Programs for Calculating and Displaying Earthquake Fault-plane Solutions, U.S. Geological Survey Open-File Report 85-739, 109 pp.

Richter, C. F. (1935). An instrumental earthquake scale, Bulletin of the Seismological Society of America 25, 1-31.

Wald, D. J., J. W. Dewey, and V. Quitoriano (2000). Community Internet Intensity Maps: Examples from California earthquakes (abstract), Seismological Research Letters 71, 267.

Wald, D. J., V. Quitoriano, T. H. Heaton, H. Kanamori, C. W. Scrivner, and C. B. Worden (1999). TriNet "ShakeMaps": Rapid generation of peak ground motion and intensity maps for earthquakes in southern California, Earthquake Spectra 15, 537-556.

Wald, L. A., L. M. Jones, S. Schwarz, and L. K. Hutton (1998). The 1997 Southern California Seismic Network Bulletin, Seismological Research Letters 69, 532-549.

\section{Seismological Laboratory California Institute of Technology Pasadena, CA 91106 \\ (K.H., E.H., J.C., J.F., A.G., N.S.) kate@gps.caltech.edu}

Pasadena Field Office U.S. Geological Survey 525 S. Wilson Avenue Pasadena, CA 91106

(D.G., A.Y.) 